\title{
Encapsulation of Glycosides from Extract Plantago Major in ZnO Matrices by Sol-Gel
}

Javier Aguila Rosas ${ }^{1}$, J. Albino Moreno Rodriguez ${ }^{*}$, Alfonso D. Díaz Fonseca ${ }^{1}$, Alan E. Aguilar Aguilar ${ }^{1}$, Carmen M. Atzin Macedo ${ }^{1}$, Verónica Santander Vázquez ${ }^{2}$, Claudia Santander Vázquez ${ }^{2}$, Efrain Rubio Rosas ${ }^{3}$ and Lilián A. Moreno Rodríguez ${ }^{4}$

1. Chemistry Department, Faculty of Chemistry Science, Benemérita Universidad Autónoma de Puebla, C.U. Colonia San Manuel. Puebla 72570, Mexico

2. Faculty of Chemical Engineering, Benemérita Universidad Autónoma de Puebla, C.U. Colonia San Manuel. Puebla 72570, Mexico

3. Academic entailment Center and technology transfer, Benemérita Universidad Autónoma de Puebla, C.U. Colonia San Manuel. Puebla 72570, Mexico

4. Physics Institute, Benemérita Universidad Autónoma de Puebla, C.U. Colonia San Manuel. Puebla 72570, Mexico

\begin{abstract}
Today burns are one of the 20 leading causes of disease, with high incidence. Males are the most affected with $52 \%$ and the age group most often is 1-4 years [1]. Therefore is necessary to provide a good choice of dressing (healing material that is painless during application) used like an aid in burns treatment, a dressing has to be cost effective, easy to use and accessible, with minimal side effects, antimicrobial and non- toxic. This investigation is focused to synthesize structures matrices of plants with activity pharmacological like chromogenic glycosides such catapol and aucubin who are presents in plantain leaves [2]. These glycosides have shown to have anti-inflammatory effects, bacteriostatic and healing in wounds and burns treatment. An important part is the characterization of the matrices by spectrophotometric analysis using UV-Visible, FTIR, XRD, SEM and EDS, showing that ZnO has a hexagonal crystal form type, the particle size is approximately of $200 \mathrm{~nm}$ average.
\end{abstract}

Key words: Encapsulation, nanomatrices of ZnO, plantago major, glycosides, SEM, sol-gel.

\section{Introduction}

Plantago major is a perennial herbaceous perennial with unbranched stems underground. Popularly known as "llantén mayor", "llantén común" o "llantén grande". Plantago is a nonculturable plant, easy to locate and regarded like weed. This plant common and easily to found in grassland areas, slopes, near crops and in roadsides.

Plantago major (shown in Fig. 1) has a hudge potential and it is useful for its anti-inflammatory, antibacterial, astringent and anti-hemorrhagic properties, also it is used to wound healing internal and

Corresponding author: J. Albino Moreno Rodriguez, Ph.D., professor, research fields: synthesis of nanocatalysts, nanosupports, nanoparticles, ion exchange, impregnation, precipitation and sol-gel. E-mail: albinomx@yahoo.com. external with bibliographic studies that corroborate the use of active ingredients to accelerate the healing process. Also it is known that the same specie contains tannins and allantoin who are auxiliary to early regeneration of skin [5].

Furthermore, we used a better extraction of active ingredients because only had reference of its traditional use by infusions. We used the Soxhlet extraction equipment for high performance obtained [6].

$\mathrm{ZnO}$ was used to form nanomatrices for being soluble in alcohol, in addition to its medicinal use is used for treating allergies, irritation and surface wounds having an astringent effect which protects against infections and accelerates the healing process. [7].

We performed synthesis of nanomaterials by the 
sol-gel method; glycosides were encapsulated in $\mathrm{ZnO}$ matrices for three reasons: first because it is an alternative allows the use of the glycosides; second is to use the properties of the matrices, slow release and active principle and the third to increase the therapeutic effect of $\mathrm{ZnO}$ as matrices causing synergism.

Spectrophotometric techniques were used UV-Vis and FTIR for glycosides characterization, the study of zinc oxide in nano matrices with glycosides were also characterized by UV-Vis, FTIR and X-ray diffraction to determine its crystalline structure, in addition SEM to identify several structural features for subsequent application.

To determine the functionality of encapsulated extract $\mathrm{ZnO}$ and pharmacological activity, it was determined through an experimental animal model doing wounds in rats and applying nanomatrices for evaluating drug dosage and use as a dressing.

\section{Experiments}

The Using $10 \mathrm{~g}$ of crushed leaves and a No.44 mesh

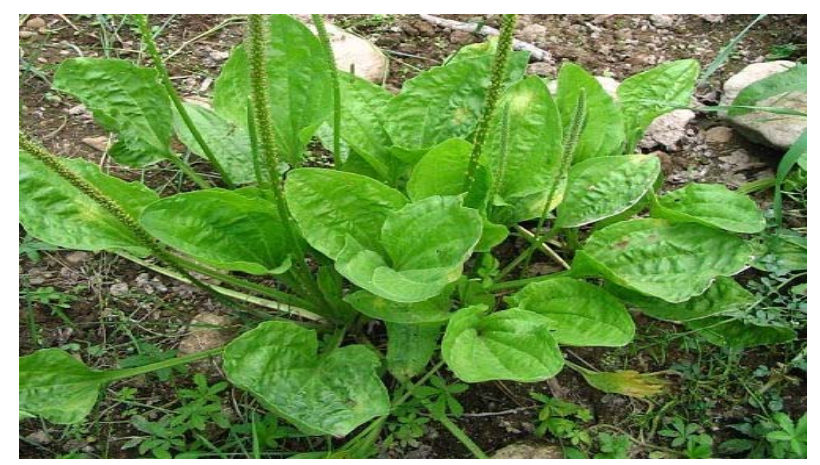

Fig. 1 Plantago major [2].

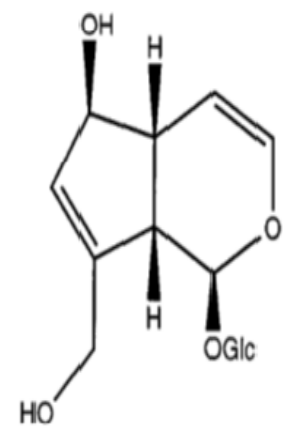

Aucubina

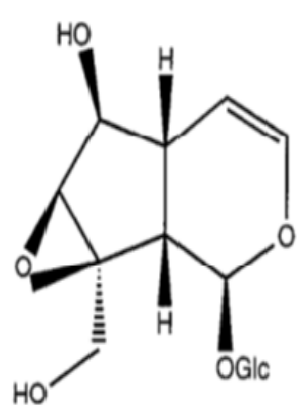

Catalpol
Fig. 2 Iridoid glycosides from P. major [3]. sieve, then placed in cartridges of porous filter paper and were closed, subsequently they entered into the Soxhlet and reflux. Extraction is performed at a constant temperature range of $65^{\circ}$ to $70{ }^{\circ} \mathrm{C}$ with an alcohol-water mixture (7:3) $2 \mathrm{~h}$. After returning the solvent to extract stops the process so that it retains the pharmacological effect and not decompose aucubin. The extract concentrated in a rotary evaporator to remove $60 \%$ of solvent.

Subsequently $5 \mathrm{~g}$ of $\mathrm{ZnO}$ are weighed and dissolved by stirring with a mixture of $100 \mathrm{~mL}$ of EtOH and $6 \mathrm{ml}$ distilled water until the mixture appears homogeneous, add $1 \mathrm{~g}$ of polyvinylpyrrolidone and the stirring is continued to doping with the extract and poured into the ball flask to performing the synthesis.

Take representative samples to work them into teams UV-Vis, FTIR, XRD and SEM previously prepared to the requirements of each studio.

\section{Experimental Results}

\subsection{UV-Vis Spectrophotometry}

The following Figs. 3 and 4 show the spectra of extract and nanomaterials observed at different wavelengths and different bands.

The value of $\mathrm{Eg}$ of aucubin/ $\mathrm{ZnO}$ compared to $\mathrm{ZnO}$ is $>1 \%$. Shifts to lower energy regions of the electromagnetic spectrum. Materials aucubin/ZnO and $\mathrm{ZnO}$ present a frequency in $\mathrm{Hz}$ [x1014] of 7.45 and 7.37 respectively; both have an absorbance in the zone

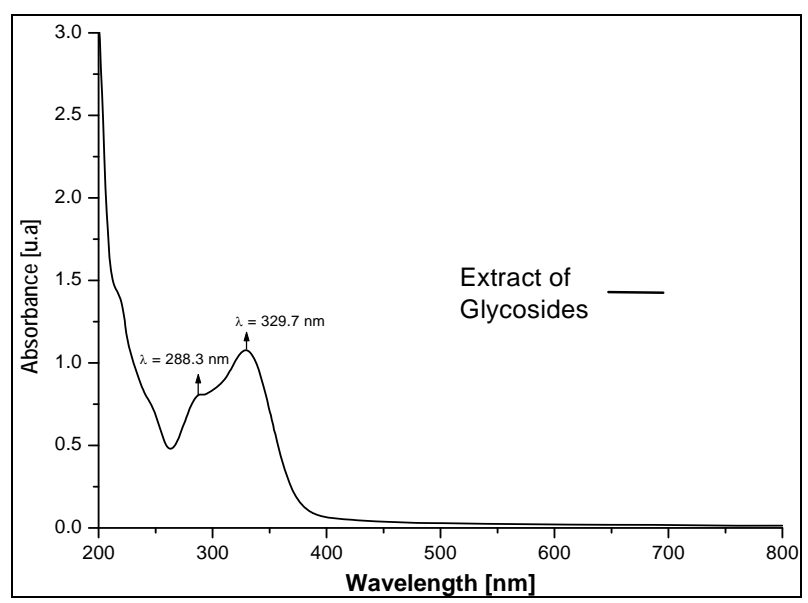

Fig. 3 UV-Vis spectrum of extract. 


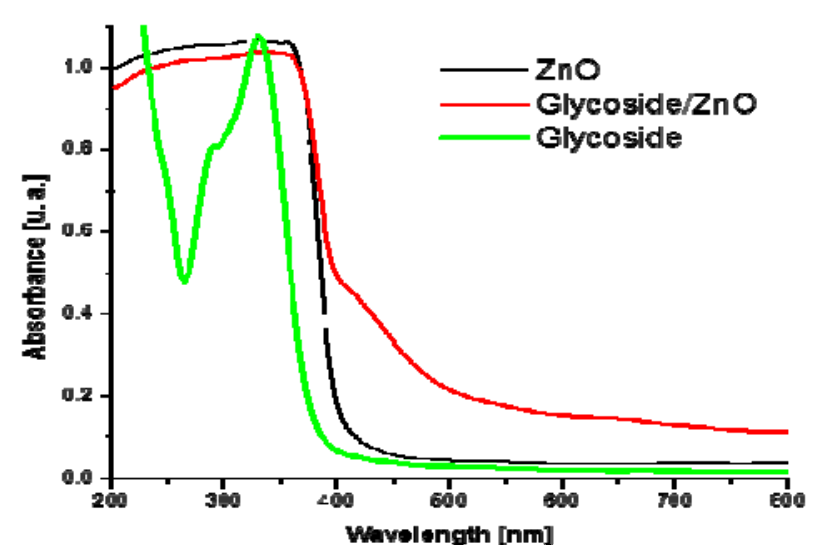

Fig. 4 UV-Vis spectrum of the nanomaterial ZnO/aucubin and $\mathrm{ZnO}$.

limits of UV-Vis spectrum such is indicated in the next Table 1.

Aucubin extract has two absorption bands in the UV region. The maximum band is located at $329.7 \mathrm{~nm}$ (electronic transitions $\sigma>\sigma^{*}$ ) of the single bonds between $\mathrm{C}-\mathrm{H}$ and $\mathrm{C}-\mathrm{C}$ of aucubin. The absorption band is least at $288.3 \mathrm{~nm}$ (electronic transitions $\mathrm{n} \rightarrow \pi^{*}$ ) assigned to carboxylate functional groups and substituted phenyl.

\subsection{DRX}

In the study of X-ray diffraction is observed that the material aucubin / $\mathrm{ZnO}$ is crystal and corresponds to $\mathrm{ZnO}$ hexagonal, such shown in Figs. 5 and 6.

\subsection{Infrared Spectroscopy (FTIR)}

The spectrum infrared of aucubin it shown in Figs. 7 and 8 . We have indicated several bands, one is located in $2088.6 \mathrm{~cm}^{-1}$ corresponds to the interaction of species $\mathrm{C}-\mathrm{H}$ from benzene ring and in $1638.4 \mathrm{~cm}^{-1}$ presents the

Table 1 Optical and electronic properties of $\mathrm{ZnO}$ materials, aucubin / ZnO.

\begin{tabular}{lllll}
\hline Materials & $\lambda(\mathrm{nm})$ & $\mathrm{E}(\mathrm{eV})$ & $v(\mathrm{~Hz})$ & Spectral region \\
\hline $\mathrm{ZnO}$ & 402.9 & 3.07 & 7.45 & $\mathrm{UV}-V$ is (violet) \\
aucubin /ZnO & 407.1 & 3.04 & 7.37 & $\mathrm{UV}-V$ is (violet) \\
\hline
\end{tabular}

Table 2 Optical and electronic properties of the aucubin material.

\begin{tabular}{lllll}
\hline Material & $\lambda(\mathrm{nm})$ & $\mathrm{E}(\mathrm{eV})$ & $v(\mathrm{~Hz})$ & Spectral region \\
\hline \multirow{2}{*}{ Aucubin } & 329.7 & 3.75 & $9.1 \times 10^{14}$ & UV(nearby) \\
& 288.3 & 4.29 & $1.0 \times 10^{15}$ & $\mathrm{UV}($ far $)$ \\
\hline
\end{tabular}

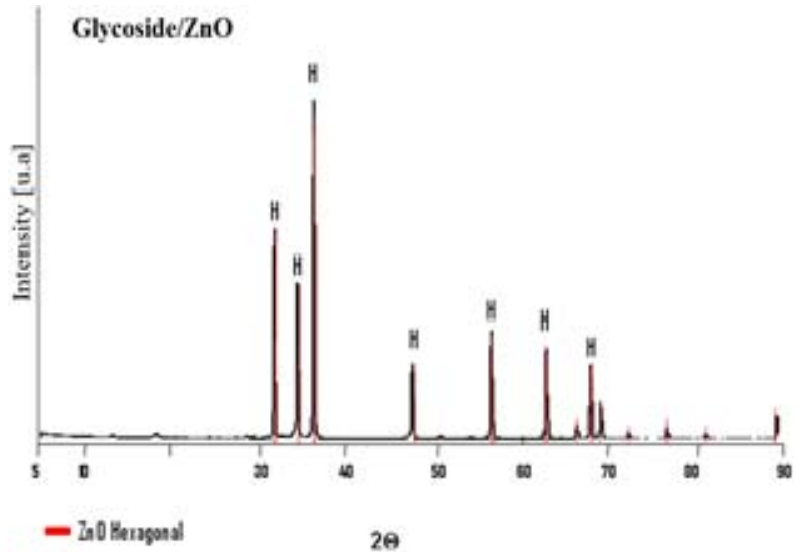

Fig. 5 Spectrum DRX of nanomaterial aucubin/ZnO.

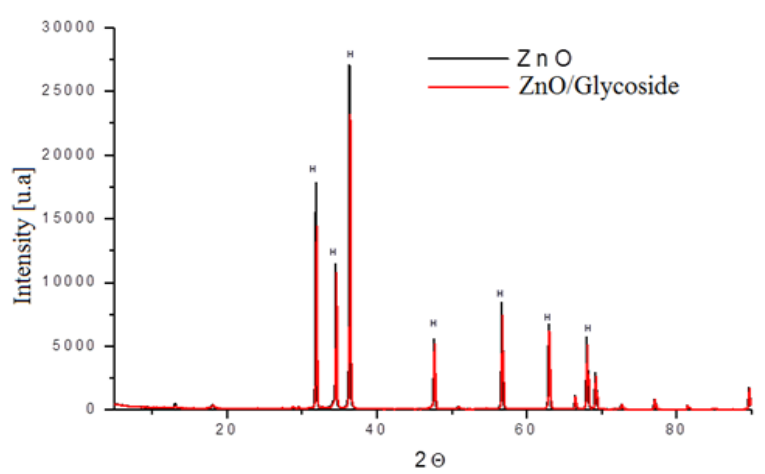

Fig. 6 Difference between spectra DRX of nano-material $\mathrm{ZnO} /$ glycoside and ZnO.

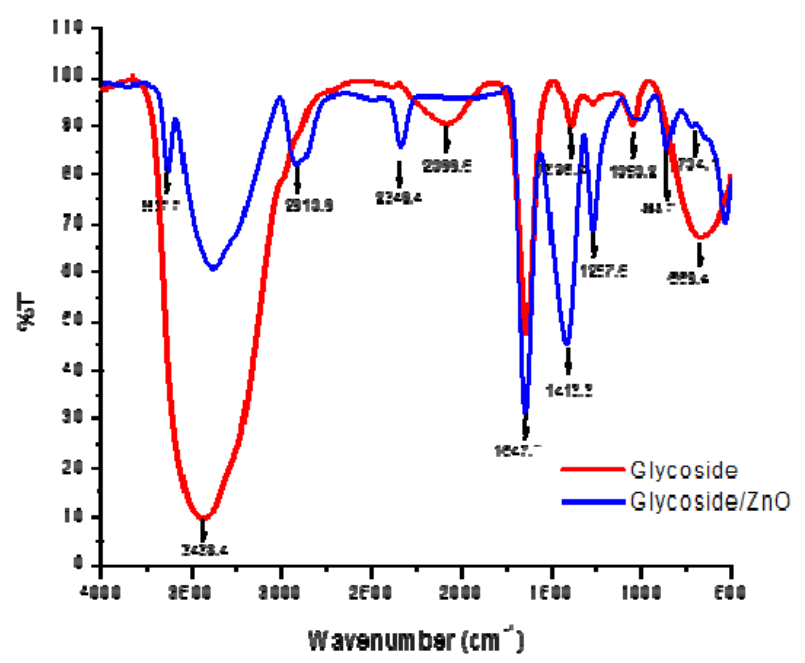

Fig. 7 Infrared spectrum of nanomaterial aucubin/ZnO and glycoside aucubin.

vibration mode $\mathrm{C}-\mathrm{C}$ of the annular ring and vibration odes of OH-type bending. Towards $1,396.4 \mathrm{~cm}^{-1}$ is localized interaction of the double bond carbons of benzene ring. The absorption bands at $1,276.2 \mathrm{~cm}^{-1}$ and $1051.9 \mathrm{~cm}^{-1}$ are assigned to the ether group (nR-O-R) 


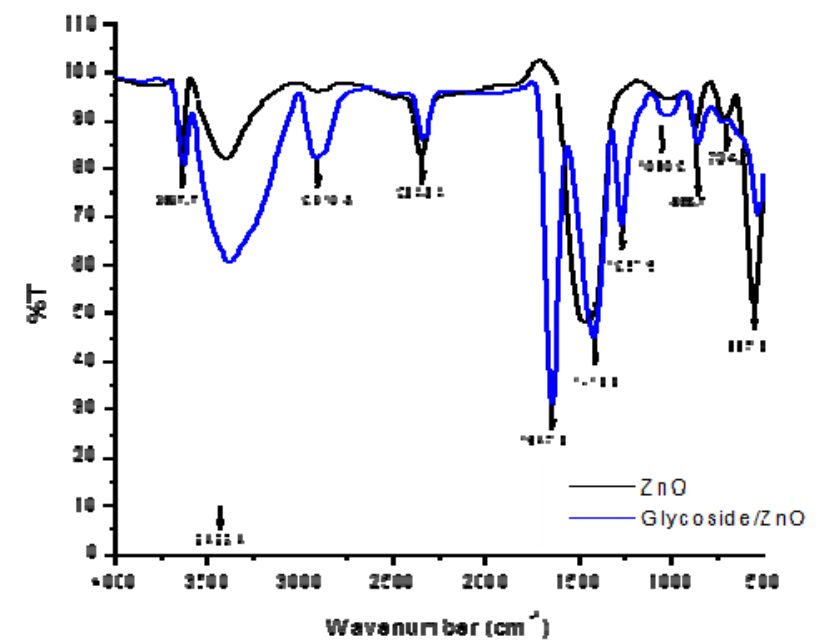

Fig. 8 Infrared spectrum of nanomaterial aucubin/ZnO and $\mathrm{ZnO}$.

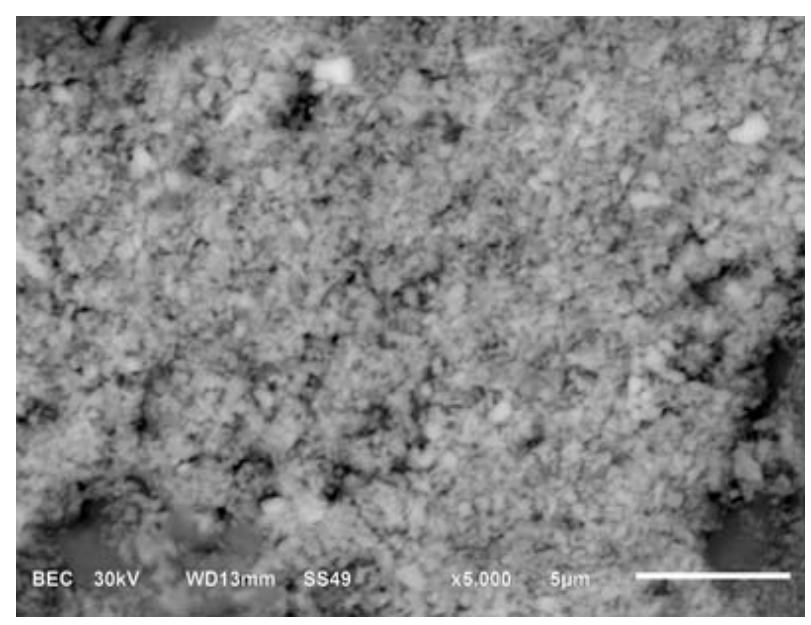

Fig. 9 Microscopy of nanomatrices at 5000x.

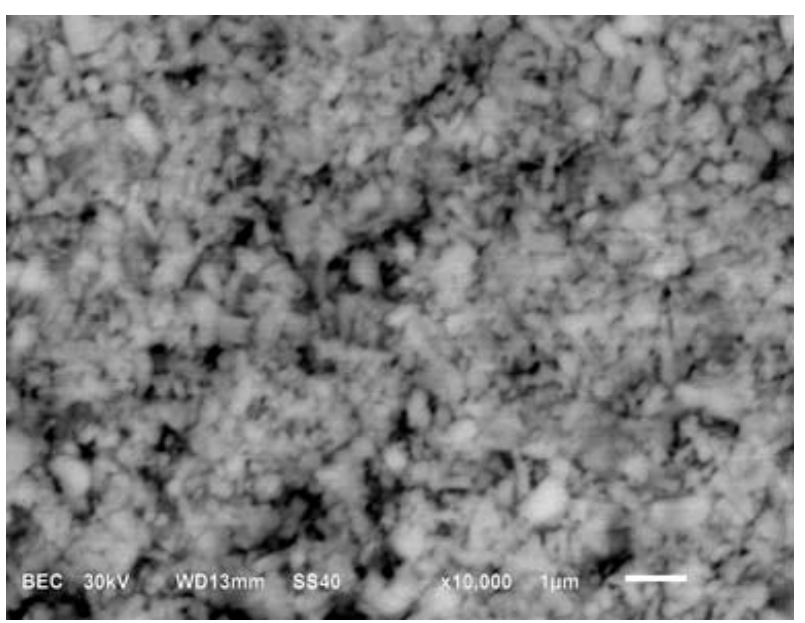

Fig. 10 Microscopy of nanomatrices at 10000x.

and in $669.4 \mathrm{~cm}^{-1}$ interaction is located species Csp2 with $\mathrm{H}$ out of plane.

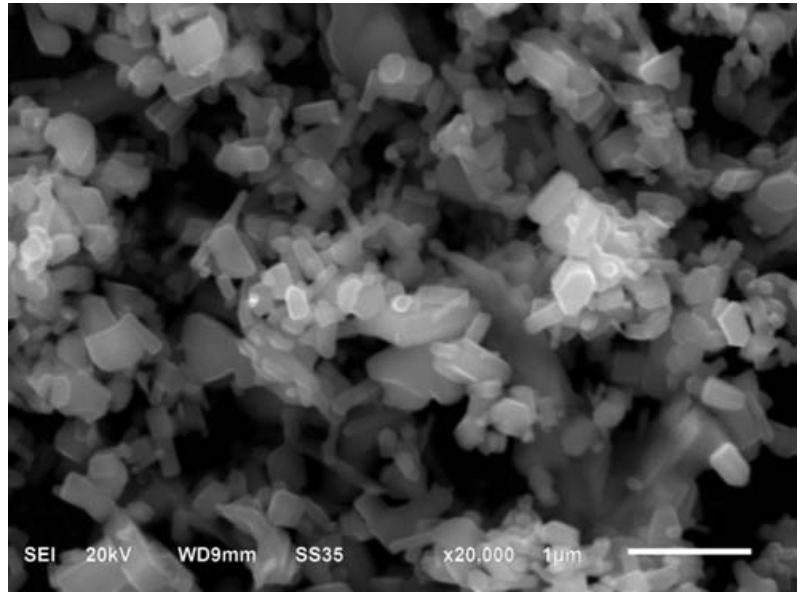

Fig. 11 Microscopy of nanomatrices at 20000x.

Table 3 EDS of $\mathrm{ZnO} /$ glycoside.

\begin{tabular}{lll}
\hline Element & Weight (\%) & Atomic (\%) \\
\hline Zinc (Zn) & 61.30 & 30.68 \\
Oxygen (O) & 30.69 & 62.78 \\
Carbon (C) & 8.01 & 6.54 \\
\hline Total & 100.00 & \\
\hline
\end{tabular}

Table 4 EDS of ZnO.

\begin{tabular}{lll}
\hline Element & Weight (\%) & Atomic (\%) \\
\hline Oxygen $(\mathrm{O})$ & 28.12 & 61.51 \\
Zinc $(\mathrm{Zn})$ & 71.88 & 38.4 \\
\hline Total & 100.00 & \\
\hline
\end{tabular}

\subsection{Scanning Electron Microscopy (SEM)}

The average particle size by SEM is about $200 \mathrm{~nm}$ and has a morphology uniform with elongated semi particle like shown in the following microscopies.

\subsection{Energy Dispersive Spectroscopy (EDS)}

The result for EDS, sample the percentage semiquantitative of each element and atomic mass of materials present in the nanomaterial aucubin/ZnO. It shows a weight centesimal mass: 61.30 of $\mathrm{Zn}, 30.69$ of $\mathrm{O} 2$ y 8.01 of C. described in the Table 3. So different from the composition of only $\mathrm{ZnO}$ shown in Table 4.

\section{Conclusions}

According to the analysis applied especially SEM-EDS and FTIR we can establish aucubin like a glycoside present in the mesh of $\mathrm{ZnO}$, by the presence 
of carbon and oxygen. Therefore these nanomaterials are ready to be applied on a wound injury model in rats to assess its healing activity.

\section{Acknowledgments}

The authors wish to express their appreciation to M. S. P. Fernando Moreno Rodriguez, Tapia's Chiautla Hospital, 11th street North Highway to Ixcamilpa, S/N, C.P. 74730, Puebla. Mexico and M. C. José Guadalupe Quiroz M. C. director of the Chemical Faculty of the BUAP. Puebla, Pue., México.

\section{References}

[1] Asociación Mexicana para el Cuidado integral Y Cicatrización de Heridas A.C. Dir. Puente de Piedra Col. Toriello Guerra Tlalpán 14050 DF email. amicichac@amcichac.com(accessed September 24, 2012).

[2] Descripción-fitoterapia by etnobotania.

[3] http://mx.globedia.com/llanten-mayor (accessed April 17, 2012).

[4] Vibrans, H. 2009. Malezas de México, Plantago Major, Accessed January 26, 2013. http://www.conabio.gob.mx/malezasdemexico/plantagina ceae/plantago-major/fichas/ficha.htm.

[5] Samuelsen, A. B. 2000. "The Traditional Uses, Chemical Constituents and Biological Activities of Plantago Major L.” A review. J. Ethnopharmacol.

[6] Martínez V. 2005. El mundo de las plantas. Botanical.
$<$ http://www.botanical-online.com/ medicinalsllanten.htm>

[7] http://www.cenunez.com.ar/archivos/39-Extraccinconequ ipoSoxhlet.pdf

[8] S.S.A. Catálogo de Medicamentos Genéricos Intercambiables para farmacias y público en general. www.facmed.unam.mx/bmnd/gi_2k8/prods/PRODS/Óxid o\%20de\%20zinc.htm (accessed September 16, 2012).

[9] Jentoft, F. C. 2004. "Diffuse Reflectance IR and UV-Vis Spectroscopy Fritz-Haber-Institute der Max-Planck-Gesellschaft.” Espectroscopia Ultravioleta-Visible.

[10] Asociación Mexicana de Microscopía A.C. 2012 http://amemi.org/

[11] Tecnologico de Costa Rica 2007, Biblioteca, editorial tecnologica, Revista Tecnologica Marcha.

[12] http://www.tec.ac.cr/sitios/Vicerrectoria/vie/editorial_tec nologica/Revista_Tecnologia_Marcha/pdf/tecnologia_ma rcha_21-2/21-2\%2017-24.pdf (accessed August30, 2012).

[13] Taskova, R., Handjieva, N., Evstatieva, L., and Popov, S. 1999. "Iridoid Glucosides from Plantago Cornuti, Plantago Major and Veronica Cymbalaria." Phytochemistry 52: 1443-5.

[14] Skari, K. P., Malterud, K. E., and Haugli, T. 2000. "Radical Scavengers and Inhibitors of Enzymatic Lipid Peroxidation from Plantago Major, a Medicinal Plant." Years of Natural Products Research 495.

[15] Samuelsen, A. B., Lund, I., Djahromi, J. M., Paulsen, B. S., Wold, J. K., and Knutsen, S. H. 1999. "Structural Features and Anti-Complementary Activity of Some Heteroxylan Polysaccharide Fractions from the Seeds of Plantago Major L." Carbohydrate Polymers 38: 133-143. 